\title{
A Rede INOVATEC/Finep e sua Contribuição ao SINAT/PBQP-Habitat e à Norma Brasileira NBR 15575
}

\author{
Claudio de Souza Kazmierczak \\ Márcio Minto Fabricio
}

A Rede de Pesquisa "Desenvolvimento de métodos e metodologias para avaliação de desempenho de tecnologia inovadoras no Âmbito do Sistema Nacional de Avalição Técnica”, denominada Rede INOVATEC, foi implementada em 2011 por meio do edital n. 07/2009 da Finep - Inovação e Pesquisa.

A rede foi criada com o objetivo de desenvolver e aprimorar critérios de desempenho e novos métodos de avaliação relativos à durabilidade e à vida útil de projeto de produtos e sistemas construtivos inovadores que possam subsidiar futuras diretrizes SINAT (Sistema Nacional de Aprovações Técnicas), sistema concebido em 2007 dentro do PBQP-H (Programa Brasileiro de Qualidade e Produtividade do Habitat). A rede é inspirada pelas demandas decorrentes da implementação da Norma 15575: Edifícios Habitacionais - Desempenho (ABNT, 2013), e pretende propor adequaçóes e complementar os métodos e critérios SINAT à nova Norma.

A Rede INOVATEC/FINEP foi estruturada em cinco subprojetos que tratam de diferentes temáticas, além de um subprojeto específico para a gestão e articulação da rede. São elas:

I - Durabilidade: avaliação da durabilidade de materiais, componentes e elementos construtivos inovadores;

II - Ambiental: avaliação ambiental de materiais e componentes de sistemas construtivos inovadores;

III - SINAT: contribuiçóes ao aperfeiçoamento da NBR 15575 e do SINAT; 
IV - Uso e Manutenção: elaboração de manuais para a avaliação da gestão da qualidade do projeto e de tecnologias construtivas inovadoras;

V - Estrutura: definição de procedimentos para a avaliação estrutural de sistemas constritivos inovadores.

Parte dos resultados das pesquisas realizadas pela rede são compilados em livros organizados segundo os subprojetos da pesquisa.

No primeiro livro, publicado em 2015 e intitulado "Avaliação de Desempenho de Tecnologias Construtivas Inovadoras - Manutenção e Percepção dos Usuários”, constam resultados de trabalhos efetuados nos subprojetos "SINAT" e "Uso e Manutenção".

Neste segundo livro, é apresentada uma coletânea de contribuiçóes de pesquisadores participantes dos subprojetos "Durabilidade", "Ambiental" e "Estrutura", provenientes das seguintes instituições: FT/UNICAMP Faculdade de Tecnologia da Universidade de Campinas; FZEA/USP Faculdade de Zootecnia e Engenharia de Alimentos da Universidade de São Paulo; IAU/USP - Instituto de Arquitetura e Urbanismo da Universidade de São Paulo; IFPB - Instituto Federal de Educação, Ciência e Tecnologia da Paraíba; UNISINOS -Universidade do Vale do Rio dos Sinos; UFRN Universidade Federal do Rio Grande do Norte e UFRGS - Universidade Federal do Rio Grande do Sul.

O segundo livro é dividido em doze capítulos, sendo um introdutório e os demais abordando diversos temas relacionados com as pesquisas realizadas nos subprojetos da Rede INOVATEC/FINEP. Coube aos pesquisadores responsáveis pelas instituiçôes já citadas escolher, dentre as atividades desenvolvidas por suas instituiçôes durante os trabalhos da rede, um tema relacionado a suas Metas, com prioridade aos subprojetos Ambiental, Sustentabilidade ou Estrutura, e coordenar a elaboração de um capítulo sumarizando a contribuição alcançada. Os capítulos foram organizados em função dos subprojetos da Rede, numa sequência que procura associar temas similares.

O capítulo 1 realiza uma breve introdução e contextualização sobre a Rede INOVATEC/FINEP, e descreve de forma sucinta os demais capítulos deste volume. 
Os capítulos dois e três discutem aspectos relacionados à reciclagem de resíduos em materiais de construção civil, com foco na avaliação ambiental de materiais utilizados em sistemas construtivos inovadores.

O segundo capítulo faz uma revisão sobre resíduos de construção civil e resíduos industriais, apresenta dados sobre a política nacional de resíduos sólidos, descreve a forma como as normas brasileiras classificam resíduos sólidos e discute alguns aspectos da Resolução 307 do CONAMA. Na sequência, são listadas algumas técnicas utilizadas para a avaliação da estabilização e solidificação de resíduos industriais para uso na construção civil, considerando os parâmetros da NBR10004.

O terceiro capítulo discute de forma mais aprofundada a avaliação ambiental de produtos e sistemas construtivos inovadores com resíduos. São apresentados os conceitos de lixiviação, solubilização e estabilização por solidificação com foco em componentes utilizados na construção civil. A estabilidade de resíduos incorporados a materiais de construçáo com matriz de cerâmica vermelha e de cimento Portland é discutida, sendo apresentada uma revisão sobre os principais métodos utilizados para a extração do lixiviado. Por fim, a forma de avaliação proposta pela ABNT NBR10004 é criticada, sugerindo-se um novo método para a avaliação ambiental de produtos e sistemas construtivos inovadores com resíduos.

Nos capítulos quatro a dez são apresentados estudos relacionados com a durabilidade de sistemas construtivos inovadores.

O quarto capítulo tem o objetivo de fornecer subsídios para a avaliação do potencial deletério decorrente do uso de resíduos em matrizes cimentícias. A partir de um estudo exploratório, foram identificados 37 tipos de resíduos cuja aplicação na construção civil vem sendo objeto de pesquisas, e para cada um deles foi realizado um levantamento de dados visando sua caracterização química e mineralógica e identificados os principais processos de degradação esperados a partir de sua incorporação a uma matriz de cimento Portland. O trabalho propóe, a partir de um fluxograma, uma sistematização para a análise do efeito deletério da incorporação de resíduos em concretos e argamassas.

O quinto capítulo apresenta uma relação de métodos de ensaio utilizados para a avaliação da indução da corrosão a partir da penetração de cloretos em concreto armado, discutindo suas particularidades, e expóe os resultados de um estudo experimental em concreto armado com adição de resíduos 
de cerâmica vermelha (obtidos pela moagem de tijolos). No estudo, são comparados diferentes métodos acelerados de indução da corrosão, concluindo-se que para este tipo de resíduo os métodos de imersão e secagem são mais apropriados e permitem uma avaliação mais adequada do processo de corrosão.

O sexto capítulo apresenta uma metodologia para a avaliação da durabilidade de revestimentos de argamassa aplicados sobre alvenaria de cerâmica vermelha. É realizada uma revisão sobre os mecanismos de deterioração a que as alvenarias do sistema de fechamento vertical de edifícios estão sujeitas. Discute-se ainda diversos métodos de ensaio que podem ser utilizados para a avaliação de sua deterioração. A partir de um programa experimental, em que alvenarias de cerâmica vermelha revestidas com argamassa com incorporação de resíduos obtidos pela moagem de concreto são submetidas ao ensaio acelerado com ciclos de exposição ao calor e choque térmico por aspersão de água especificado na ABNT NBR 15575-4, é realizada a determinação do nível de degradação do revestimento, a partir de diversos métodos de avaliação, e criticada a eficiência de cada um dos métodos.

No sétimo capítulo são avaliadas metodologias de envelhecimento acelerado para painéis de partículas de bagaço de cana-de-açúcar. São apresentados os conceitos relacionados com a durabilidade, os mecanismos e agentes de degradação que interferem no desempenho dos painéis, assim como metodologias utilizadas para a sua avaliação. Em particular, é apresentada uma metodologia para a avaliação comparativa da durabilidade a partir de ensaios entre painéis com partículas de bagaço de cana-de-açúcar com resina bicomponente à base de óleo de mamona e painéis de partículas de madeira comerciais (Medium Density Particleboard) e resina de ureia-formaldeído.

O oitavo capítulo discute a previsão de vida útil de estruturas de concreto. São listadas as principais normas internacionais referentes à durabilidade e a previsão de vida útil de sistemas estruturais em concreto, e apresentadas noçōes sobre desempenho, durabilidade e vida útil. É proposta uma metodologia para a modelagem e a previsão da vida útil de estruturas de concreto, a partir do levantamento de dados de degradação e de sua simulação, segundo dois modelos de degradação. Além disso, são discutidos os principais parâmetros que geram variabilidade nas propriedades do concreto armado. 
Nos capítulos nove e dez são apresentadas contribuições para a avaliação estrutural de sistemas construtivos baseados em terra, sendo um sobre alvenarias com blocos de terra compactada e o outro sobre o uso de taipa.

O nono capítulo descreve uma metodologia para a avaliação estrutural de alvenarias construídas com blocos de terra compactada. É realizada uma pequena revisão sobre estruturas de terra, sobre o comportamento mecânico de alvenarias e sobre os tipos de carregamento e formas de ruptura esperados. Sáo apresentados a metodologia e os resultados de um estudo experimental de ruptura de dois tipos de alvenarias com blocos de terra compactada, uma na forma de "L" e outra com uma abertura, abordando-se as particularidades dos resultados em função do comportamento frágil do material "terra".

No décimo capítulo é realizada uma avaliação de composição de solo para uso em taipa a partir de um estudo de caso. São apresentadas as formas de execução de taipa e discutidas algumas deficiências deste tipo de sistema construtivo. $\mathrm{O}$ capítulo apresenta os resultados de um estudo de caracterização de dois tipos de solo utilizados na construção de taipa, comparando suas características com a durabilidade esperada para cada sistema.

Por fim, nos dois capítulos que encerram este livro são discutidos critérios para a avaliação do potencial de desmonte e a metodologia para avaliação do ciclo de vida de sistemas construtivos.

No décimo primeiro capítulo são listados diversos critérios para a avaliação do potencial de desmonte e reciclagem de um sistema construtivo inovador a serem utilizados na etapa de projeto. É discutida a influência do tipo de conexóes no processo de desmontagem de sistemas construtivos e avaliada a forma como pode ser realizada a reciclagem da madeira, do aço, de alvenarias e do concreto. São apresentados critérios para a avaliação do potencial de desmonte, além de proposto um checklist para a caracterização de sistemas construtivos, com relação à facilidade de desmonte.

No décimo segundo capítulo é descrita a metodologia para avaliação do ciclo de vida de sistemas construtivos, explicando-se como são realizados a definição de objetivo e escopo, a análise de inventário de ciclo de vida, a avaliação de impacto de ciclo de vida e a interpretação de ciclo de vida.

O segundo livro da rede INOVATEC/ FINEP consolida as contribuiçóes de pesquisadores brasileiros para o estudo e a discussão da temática desempenho, durabilidade e sustentabilidade de produtos e sistemas 
construtivos inovadores, apresenta colaboraçóes para aprimoramento do Sistema Nacional de Avaliação Técnica e compõe um conjunto de referências atualizadas para empresas e pesquisadores envolvidos com a avaliação e desenvolvimento de sistemas construtivos inovadores. 